\title{
Determining the Prevalence of and the Factors Associated with Antihypertensive Medication Non-Adherence in the Gaza
}

\section{Strip}

\author{
Khalid Khadoura ${ }^{1,2}$, Elham Shakibazadeh ${ }^{3}$, Mohammad Ali Mansournia $^{4}$, Yousef Aljeesh ${ }^{5}$, Akbar Fotouhi $^{4, *}$ \\ 'Department of Epidemiology and Biostatistics, School of Public Health, Tehran University of Medical Sciences International Campus, Tehran, Iran \\ ${ }^{2}$ Department of Nursing, Faculty of Health Professions, Israa University, Gaza, Palestine \\ ${ }^{3}$ Department of Health Education and Promotion, School of Public Health, Tehran University of Medical Sciences, Tehran, Iran \\ ${ }^{4}$ Department of Epidemiology and Biostatistics, School of Public Health, Tehran University of Medical Sciences, Tehran, Iran \\ ${ }^{5}$ Faculty of Nursing, Islamic University of Gaza, Gaza, Palestine
}

\section{See editorial commentary page on $\mathbf{8 9}$}

Background: This study aimed to estimate the prevalence of and determine the factors associated with antihypertensive medication (A-HTNM) non-adherence among hypertension care seekers attending primary health clinics in the Gaza Strip.

Methods: A cross-sectional survey was conducted as the recruitment phase of a clustered randomized controlled trial including 538 participants. The participants were randomly selected from 10 primary health care centers by two-stage cluster random sampling. A structured questionnaire was used to collect data through face-to-face interview. The questionnaire was developed based on the World Health Organization determinants for medication non-adherence and the Health Belief Model. The main outcomes of this study were the prevalences of A-HTNM non-adherence and its associated factors. Adherence status was assessed using the eight-item Morisky Self-Report Medication Adherence Scale. Data were analyzed by STATA ver. 14.0 (Stata Corp., College Station, TX, USA) using a standard complex survey, accounting for unresponsiveness and the clustering sampling approach.

Results: The overall prevalence of A-HTNM non-adherence was 65.8\% (95\% confidence interval [CI], 59.2-71.8). Among all studied predictors, only self-efficacy of participants (odds ratio [OR], 3.8; 95\% CI, 1.79-2.84) and social support (OR, 2.26; 95\% CI, 2.82-5.11) remained significantly associated with A-HTNM non-adherence after adjusting for age, education level, number and frequency of A-HTNM doses per day, and comorbidities.

Conclusion: The high prevalence of non-adherence highlights the need for serious intervention to enhance the adherence rate among hypertension patients. The associated factors can be considered when developing appropriate interventions.

Keywords: Antihypertensive Drugs; Medication Non-Adherence; Prevalence

Received: June 15, 2019, Revised: August 23, 2019, Accepted: September 5, 2019

*Corresponding Author: Akbar Fotouhi https://orcid.org/0000-0002-6438-6833

Tel: +98-21-88992970, Fax: +98-21-88989664, E-mail: afotouhi@tums.ac.ir 


\section{INTRODUCTION}

Hypertension (HTN) was the sixth leading cause of death in Palestine in 2016, ${ }^{1)}$ with a prevalence rate of $27.6 \%{ }^{2)}$ HTN is associated with community and individual burden through increased risk of stroke, heart, and kidney diseases. ${ }^{3)}$ The goal for patients with HTN is to achieve a blood pressure (BP) lower than 130/80 $\mathrm{mm} \mathrm{Hg.}{ }^{4}$ The availability of a large number of antihypertensive medications (A-HTNM) indicate the progress in the management of HTN in the last 5 years, ${ }^{5)}$ although the rates of BP control and outcomes in HTN patients remain suboptimal as most of the efforts are directed to study the effects of medications, while little attention is paid on determining whether patients take these medications as prescribed or not. ${ }^{6)}$ In 2003, the World Health Organization (WHO) advocated the term "adherence" to describe patients' active, voluntary, and collaborative involvement in a mutually acceptable course of behavior to produce therapeutic results. According to the $\mathrm{WHO}$, the average rate of adherence to long-term therapy in developed countries is $50 \%$, and the rates are even lower in developing countries. ${ }^{7)}$ Adherence to medical treatment is a crucial mediator of antihypertensive treatment, while non-adherence is a strong barrier against effective BP control ${ }^{8)}$ Evidence indicates that non-adherence to chronic disease medications is common, and about $45.2 \%$ of HTN patients are non-adherent to prescribed medication regimens. ${ }^{9)}$ The WHO has conceptualized factors related to medication adherence in five domains (patient-related factors, socioeconomic factors, health condition-related factors, therapy-related factors, and healthcare system-related factors). ${ }^{10)}$ Furthermore, the Health Belief Model (HBM) has been widely used in medication adherence studies under the assumption that patients are able to make decisions about their health. ${ }^{11)}$

In this study, we aimed to estimate the prevalence of and to determine the associated factors of A-HTNM non-adherence based on the WHO determinants and HBM among HTN care seekers in primary health care centers in the Gaza Strip.

\section{METHODS}

\section{Study Design and Participants}

A cross-sectional survey was conducted between August 1 and December 30, 2018. The cross-sectional survey data were derived from the baseline data of the recruitment phase of a clustered randomized controlled trial. A total of $538 \mathrm{HTN}$ care seekers from 10 primary health care centers across the Gaza Strip governorates were enrolled. Participants were recruited by two-stage cluster random sampling. In the first stage, 10 centers were randomly selected by a stratified simple random sampling approach to select two centers from each governorate. In the second stage, we proportionally selected participants from each center using systematic random sampling based on the eligibility criteria and their agreement to be involved in the study. When any of the selected patients refused to participate, the next patient was selected.

\section{Eligibility Criteria}

Palestinian citizens attending government primary health centers in Gaza, aged above 18 years, registered as an HTN patient since at least 1 year, and taking at least one A-HTNM were eligible for this study. Patients who were diagnosed with cognitive impairment or a serious medical condition as reported by their primary care physician were excluded from the study.

\section{Measures}

A structured questionnaire was used to collect data from the participants via a 20-minute interview during clinic hours (8 AM to $2 \mathrm{PM}, 5$ days a week). The questionnaire variables in this study were exposure and outcome variables. The exposure variables included participants' characteristics (age, sex, marital status, employment, education level) and health status variables (smoking status, comorbidities, weight, height, body mass index [BMI], BP measurement, number and frequency of A-HTNM doses, and duration of HTN).

In addition, other exposure variables of interest (beliefs about medication, self-efficacy, intrinsic motivation, social support, and health system-related factors) were also assessed. The outcome variable was A-HTNM adherence.

$\mathrm{BP}$ was measured on the right arm in sitting position using a mercury sphygmomanometer after completing the interview; the result was recorded as the person's BP expressed in terms of mm Hg. Weight and height were measured using a mechanical weighing machine with a height rod (Health o Meter, McCook, IL, USA). Consequently, BMI was calculated using the WHO chart based on weight and height.

\section{Instruments}

An instrument was developed based on the WHO determinants for medication non-adherence and HBM. The first part of the questionnaire consisted of questions about the demographic characteristics and clinical history of participants. The second part involved the determination of patients' adherence status. The third part involved the evaluation of patients' understanding and perception of HTN (HBM constructs: perceived susceptibility, perceived severity, and perceived threat). The fourth domain involved the assessment of the participants' beliefs about medications (HBM constructs: perceived barriers and benefits). The fifth domain involved the determination of the participants' active participation in monitoring and decision making in relation to disease management (HBM construct: self-efficacy), and the sixth domain involved the evaluation of the participants' intrinsic motivation (HBM construct: internal cues to action). The last two domains involved the assessment of healthcare system-related factors such as relationships between patients and physicians and health system support (HBM constructs: perceived barriers and benefits).

Adherence status was assessed using the eight-item Morisky Medication Adherence Scale (MMAS-8), a known validated and reliable self-report medication adherence scale. ${ }^{12)}$

The Belief about Medication Questionnaire (Arabic version) was used to test the participants' beliefs about the use of A-HTNMs and the 
degree of acceptance of the validity and reliability observed in different cultures with some cross-cultural adaptation of the scale. ${ }^{11,13,14)}$

Self-efficacy was defined as a behavior-specific predictor, which was assessed using the modified version of the existing scale. ${ }^{15)}$ Intrinsic motivation was defined as the degree of one's motivation for a particular behavior, which was scored using the Treatment Self-Regulation Questionnaire (TSRQ); both of these tools were previously validated and are widely used. ${ }^{16)}$

An Arabic validated and reliable version of the Patient-Doctor Relationship Questionnaire-9 was used to assess the relationship between patients and doctors. ${ }^{13,17)}$ Likewise, a health care system support questionnaire was used with some modifications. ${ }^{13,18)}$

The Morisky Scale, TSRQ, and Self-Efficacy Questionnaires were translated to Arabic based on the five-step process (forward translation, expert panel, back translation, editing, and pre-testing) of translating and adapting an instrument recommended by the WHO. ${ }^{19)}$ Other covariates such as medical comorbidities were assessed using the Charlson Comorbidity Index, which is a validated and widely used weighted-index designed to evaluate disease comorbidity. ${ }^{20)}$

Content validity of the Arabic questionnaires were reviewed by panel of experts. Required changes were made to clarify any ambiguity and to ensure the comprehension of Palestinian participants after the pilot study.

Reliability tests were performed by test-retest within a period of 2 weeks. Intra-class correlation coefficients (ICC) and 95\% confidence intervals (CIs) were computed for the three questionnaires (Morisky Scale, TSRQ, and Self-Efficacy Questionnaire). Table 1 reveals the strong agreement level and statistically significant ICC; an ICC agreement level of 0.75-0.9 was considered good, while an ICC level of $>0.90$ indicated excellent reliability. ${ }^{21)}$ The lowest and highest ICC in each questionnaire ranged between 0.63 and 0.95 . However, the ICC for all other items was more than 0.75 .

Internal consistency was tested by determining the Cronbach's $\alpha$ for MMAS-8 adherent, TSRQ and Self-efficacy domains, which give the values of $0.92,0.81$, and 0.91 respectively, and 0.81 for the whole questionnaire, which is considered almost good.

\section{Definition of Antihypertensive Medications Adherence}

In this study, we depended on a self-report medication adherence scale to determine the adherence status. The MMAS- 8 by Morisky et al. $^{12)}$ was used for this purpose. It can identify the exact reasons for patients' non-adherence and why the individual is exhibiting this behavior. It consisted of eight questions that are assigned points ranging from 0 ("no" answer) to 1 ("yes" answer); a lower score indicates more adherence (0/8). The score has its own cut-off points: 0 for perfect adherence, $1-2 / 8$ for medium adherence, and $\geq 3 / 8$ for low adherence. ${ }^{12}$ )

To define the status of adherence, the MMAS- 8 scale responses were dichotomized into optimal and suboptimal adherence. Responses of $0 / 8$ were classified as optimal adherence, while responses indicating non-adherence $(\geq 3 / 8)$ and moderate adherence (1-2/8) were defined as suboptimal adherence (A-HTNM non-adherent).

The cut-off point for optimal adherence in HTN patients was $80 \%$ or more than that in patients showing A-HTNM. However, the decision to use self-report measures to identify patients with different levels of adherence was based on the suggested cut-off point of the scale used.

\section{Sample Size}

The sample size was calculated to be 165 participants, with an estimated non-adherence rate of $70 \%{ }^{22)}$ The sample size increased to 291 participants considering the effect of a cluster design by 1.5 and allowing a nonresponse rate of $15 \%$. However, the sample size was increased again to 538 participants for the purpose of conducting a controlled trial, as these data were the baseline data of a clustered randomized controlled trial.

\section{Data Analysis}

IBM SPSS ver. 23.0 (IBM Corp., Armonk, NY, USA) was used for ICC test and Cronbach's $\alpha$. One-way random effects model was performed, and the ICC was reported.

For the main analysis, a standard complex survey data analysis was performed by STATA ver. 14.0 (Stata Corp., College Station, TX, USA). We accounted for clustering using the STATA PSU option and for unequal probability of selection using sample weight variable analysis.

Table 1. ICC agreement level

\begin{tabular}{|c|c|c|c|c|c|c|}
\hline Questionnaire & No. of test (\%) & No. of retest (\%) & ICC single measure & $95 \%$ confidence interval & P-value & Cronbach's $\alpha$ \\
\hline MMAS-8 & & & 0.91 & $0.85-0.95$ & $<0.001$ & 0.92 \\
\hline Adherent & $24(47)$ & $23(45.1)$ & & & & \\
\hline Moderately adherent & $17(33.4)$ & $13(25.5)$ & & & & \\
\hline Non-adherent & 10 (19.6) & $15(29.4)$ & & & & \\
\hline $\mathrm{TSRQ}^{*}$ & & & 0.90 & $0.84-0.94$ & $<0.001$ & 0.81 \\
\hline Mean $>3$ & $50(98.0)$ & $49(96.0)$ & & & & \\
\hline Mean $\leq 3$ & $1(2.0)$ & $2(4.0)$ & & & & \\
\hline Self-efficacy* & & & 0.84 & $0.73-0.90$ & $<0.001$ & 0.91 \\
\hline Mean >3 & 44 (86.3) & 44 (86.3) & & & & \\
\hline Mean $\leq 3$ & $17(13.7)$ & $17(13.7)$ & & & & \\
\hline Cronbach's $\alpha$ for all & & & & & & 0.81 \\
\hline
\end{tabular}

ICC, intra-class correlation; MMAS-8, eight-item Morisky Medication Adherence Scale; TSRQ, Treatment Self-Regulation Questionnaire.

${ }^{*}$ On the Likert scale. 
Data were checked for quality and statistical assumption before conducting the main analysis. None of the tested variables violated the statistical assumptions; hence, there was no need to performed nonparametric tests.

Data were described using descriptive statistics, and groups were compared using the chi-square test for categorical variables. Under the standard complex survey data setting, univariable logistic regression was performed to assess the association between medication adherence state and participants' characteristic variables and other predictors. A multiple logistic regression model was used to assess the ad-

Table 2. Participants' characteristics $(n=538)$

\begin{tabular}{|c|c|c|}
\hline Characteristic & $\%$ or mean & $95 \%$ confidence interval \\
\hline \multicolumn{3}{|l|}{ Categorical variable (\%) } \\
\hline \multicolumn{3}{|l|}{ Governorate } \\
\hline North Gaza & 15.34 & $11.6-19.9$ \\
\hline Gaza city & 28.92 & $25.6-32.4$ \\
\hline Middle zone & 25.08 & $20.4-30.3$ \\
\hline Khan Yunis & 21.86 & $15.5-29.9$ \\
\hline Rafah & 8.80 & $7.1-10.8$ \\
\hline \multicolumn{3}{|l|}{ Age groups (y) } \\
\hline 28-39 & 6.98 & $2.9-15.4$ \\
\hline $40-59$ & 49.71 & $40.5-58.9$ \\
\hline$\geq 60$ & 43.31 & $30.7-56.7$ \\
\hline \multicolumn{3}{|l|}{ Sex } \\
\hline Male & 39.05 & $30.9-47.8$ \\
\hline Female & 60.95 & $52.1-69.08$ \\
\hline \multicolumn{3}{|l|}{ Marital status } \\
\hline Married & 90.43 & 83.0-94.8 \\
\hline Single & 1.87 & $0.85-4.1$ \\
\hline Divorced & 1.21 & $0.50-2.8$ \\
\hline Widowed & 6.49 & $2.8-14.1$ \\
\hline \multicolumn{3}{|l|}{ Employment } \\
\hline Employed & 13.53 & $10.7-16.9$ \\
\hline Jobless & 27.93 & 23.2-33.1 \\
\hline Retired & 13.18 & $7.2-22.9$ \\
\hline House wife & 45.35 & $36.5-54.0$ \\
\hline \multicolumn{3}{|l|}{ Level of education } \\
\hline |lliterate & 9.78 & $5.5-16.7$ \\
\hline Elementary school & 43.10 & $38.4-47.9$ \\
\hline Secondary school & 27.02 & $24.4-29.7$ \\
\hline University & 20.09 & $19.1-21.1$ \\
\hline \multicolumn{3}{|l|}{$\mathrm{BMI}\left(\mathrm{kg} / \mathrm{m}^{2}\right)$} \\
\hline Normal (18.5-24.9) & 7.56 & $6.52-9.87$ \\
\hline Overweight (25-29.5) & 27.23 & 25.58-28.95 \\
\hline Obese $(\geq 30)$ & 65.20 & $62.15-68.14$ \\
\hline \multicolumn{3}{|l|}{$\mathrm{BP}$} \\
\hline Controlled & 54.41 & $39.6-68.5$ \\
\hline Uncontrolled & 45.59 & $31.4-60.4$ \\
\hline \multicolumn{3}{|l|}{ Continuous variable (mean) } \\
\hline Age $(y)$ & 57.14 & $53.11-61.17$ \\
\hline $\mathrm{BMI}\left(\mathrm{kg} / \mathrm{m}^{2}\right)$ & 32.25 & $31.86-32.63$ \\
\hline Weight (kg) & 87.39 & $86.04-88.75$ \\
\hline Height (cm) & 164.43 & $163.90-164.97$ \\
\hline Systolic BP (mm Hg) & 131.66 & $126.78-136.53$ \\
\hline Diastolic BP (mmHg) & 83.27 & 81.53-85.02 \\
\hline
\end{tabular}

BMI, body mass index BP, blood pressure. justed effect of explanatory variables on the medication adherence rate. All significant variables at a level of 0.1 were included in the multiple regression analysis. Variables that disturbed the model were excluded by the backward stepwise elimination method. A two-sided Pvalue of less than 0.05 was considered significant.

\section{Ethical Considerations}

Prior to conducting this research study, ethical approval from Tehran University of Medical Sciences Ethical Committee (code no., IR.TUMS. SPH.REC.1396.4828) was obtained. Approval from the Palestinian Health Research Council (Helsinki committee) (PHRC/HC/322/18) was gained. The purpose of the study was explained to all participants, and they were reassured that their data will remain confidential; each participant was asked to sign a consent form prior to participation.

\section{RESULTS}

\section{Participants' Characteristics}

A total of 538 participants were included in the survey, with a $94 \%$ re-

Table 3. Participants' health status $(n=538)$

\begin{tabular}{|c|c|c|}
\hline Characteristic & $\%$ or mean & $\begin{array}{l}\text { 95\% confidence } \\
\text { interval }\end{array}$ \\
\hline \multicolumn{3}{|l|}{ Categorical variable } \\
\hline \multicolumn{3}{|c|}{ Duration of hypertension since diagnosis (y) } \\
\hline $1-5$ & 42.24 & $31.2-54.1$ \\
\hline $6-20$ & 52.57 & $43.1-61.9$ \\
\hline$>20$ & 5.19 & $3.3-7.8$ \\
\hline \multicolumn{3}{|l|}{ No. of antihypertensive medications } \\
\hline One medication & 64.42 & $59.6-68.9$ \\
\hline Two medication & 27.50 & $23.5-31.8$ \\
\hline Three and more medications & 8.08 & $54.6-11.7$ \\
\hline \multicolumn{3}{|l|}{$\begin{array}{l}\text { Frequency of antihypertensive } \\
\text { medications taken per day }\end{array}$} \\
\hline Once & 64.84 & $55.7-72.9$ \\
\hline Twice and more & 35.16 & $27.0-44.2$ \\
\hline \multicolumn{3}{|l|}{ Smoking status } \\
\hline Never & 81.42 & $76.5-85.4$ \\
\hline Former & 8.78 & $5.3-14.2$ \\
\hline Current & 9.79 & $7.9-12.1$ \\
\hline \multicolumn{3}{|l|}{ Other comorbidities } \\
\hline Low & 85.57 & $71.8-93.2$ \\
\hline High & 14.43 & $6.7-28.1$ \\
\hline \multicolumn{3}{|l|}{ Perception of blood pressure control } \\
\hline Controlled & 58.96 & $50.4-66.9$ \\
\hline Uncontrolled & 34.02 & $28.0-40.6$ \\
\hline Don't know & 7.01 & $3.1-15.1$ \\
\hline \multicolumn{3}{|l|}{ Self-rated health } \\
\hline Very poor & 3.80 & $0.9-13.9$ \\
\hline Poor & 14.87 & $8.6-24.4$ \\
\hline Fair & 39.41 & $34.2-44.8$ \\
\hline Good & 36.17 & $25.2-48.7$ \\
\hline Excellent & 57.36 & $34.1-92.0$ \\
\hline \multicolumn{3}{|l|}{ Continuous variable (mean) } \\
\hline Duration of hypertension (y) & 8.46 & $6.68-10.25$ \\
\hline
\end{tabular}


154

www.kjfm.or.kr

sponse rate. More than half $(60.95 \%)$ were women with an overall mean age of 57.1 years (95\% CI, 53.1-61.2 years). The majority were educated (90.2\%), married (90.4\%), unemployed (86.5\%), and non-
Khalid Khadoura, et al. - Antihypertensive Medication Non-Adherence

smokers (81.4\%). Obesity was the most common comorbidity among the study population, with a mean BMI of $32.25 \mathrm{~kg} / \mathrm{m}^{2}$ (95\% CI, 31.86$32.63 \mathrm{~kg} / \mathrm{m}^{2}$ ). Of the total participants, $45.6 \%$ had uncontrolled BP with

Table 4. Univariate analysis of adherent status and participants' characteristics

\begin{tabular}{|c|c|c|c|c|}
\hline Characteristic & Adherent \% & Non-adherent \% & P-value (two sided) & $\begin{array}{l}\text { Unadjusted odds ratio } \\
\text { (95\% confidence interval) }\end{array}$ \\
\hline Age (y) & & & $0.012^{*}$ & $1.03^{\dagger}(1.01-1.06)$ \\
\hline $18-35$ & 2.6 & 3.6 & & \\
\hline $36-50$ & 16.5 & 27.8 & & \\
\hline $51-65$ & 47.3 & 50.4 & & \\
\hline$>66$ & 33.6 & 18.2 & & \\
\hline Sex & & & 0.301 & \\
\hline Female & 43.6 & 36.7 & & Reference \\
\hline Male & 56.4 & 63.3 & & $1.33(0.71-2.5)$ \\
\hline Marital status & & & 0.702 & \\
\hline Not married & 10.2 & 9.2 & & Reference \\
\hline Married & 89.8 & 90.8 & & $0.89(0.42-1.89)$ \\
\hline Employment & & & 0.303 & \\
\hline Unemployed & 89.1 & 85.1 & & Reference \\
\hline Employed & 10.9 & 14.9 & & $0.69(0.31-1.56)$ \\
\hline Level of education & & & $0.028^{\dagger}$ & \\
\hline Illiterate & 6.9 & 11.3 & & Reference \\
\hline Literate & 93.1 & 88.7 & & $1.7(1.08-2.67)$ \\
\hline Body mass index $\left(\mathrm{kg} / \mathrm{m}^{2}\right)$ & & & 0.380 & \\
\hline Normal (18.5-24.9) & 8.7 & 6.9 & & Reference \\
\hline Above normal $(>25.0)$ & 91.3 & 93.1 & & $0.78(0.40-1.5)$ \\
\hline
\end{tabular}

${ }^{*}$ Statistically significant variables in multivariable regression analysis. ${ }^{\dagger} 0 \mathrm{dds}$ ratio for age as a continuous variable.

Table 5. Univariate analysis of adherent status and participants' health status

\begin{tabular}{|c|c|c|c|c|}
\hline Variable & Adherent \% & Non-adherent \% & P-value (two sided) & $\begin{array}{l}\text { Unadjusted odds ratio } \\
\text { (95\% confidence interval) }\end{array}$ \\
\hline Duration of hypertension (y) & & & $0.039^{*}$ & \\
\hline $1-5$ & 32.4 & 47.4 & & Reference \\
\hline$>5$ & 67.6 & 52.6 & & $1.88(1.04-3.37)$ \\
\hline No. of antihypertensive medications & & & $0.042^{*}$ & \\
\hline One medication & 59.0 & 67.2 & & Reference \\
\hline Two medications and more & 41.0 & 32.8 & & $1.43(1.02-2)$ \\
\hline Frequency of antihypertensive medications taken per day & & & $0.087^{*}$ & \\
\hline Twice and more & 31.6 & 37.0 & & Reference \\
\hline Once & 68.4 & 63.0 & & $1.27(0.95-1.71)$ \\
\hline Smoking status & & & 0.266 & \\
\hline Nonsmoker & 86.9 & 91.9 & & Reference \\
\hline Smoker & 13.1 & 8.1 & & $1.7(0.57-5.08)$ \\
\hline Other comorbidities & & & $0.098^{*}$ & \\
\hline High & 11.8 & 15.8 & & Reference \\
\hline Low & 88.2 & 84.2 & & $1.40(0.91-2.14)$ \\
\hline Perception of BP control & & & $0.055^{\star}$ & \\
\hline Uncontrolled & 26.1 & 48.8 & & Reference \\
\hline Controlled & 73.9 & 51.2 & & $2.7(0.97-7.56)$ \\
\hline Self-rated health & & & 0.121 & \\
\hline Poor & 46.5 & 64.1 & & Reference \\
\hline Good & 53.5 & 35.9 & & $2.05(0.76-5.51)$ \\
\hline BP measurement & & & $0.036^{*}$ & \\
\hline Uncontrolled & 34.7 & 51.3 & & Reference \\
\hline Controlled & 65.3 & 48.7 & & $1.98(1.06-3.68)$ \\
\hline
\end{tabular}

$\mathrm{BP}$, blood pressure.

*Statistically significant variables at a level of 0.1 included in multivariable regression analysis. 
mean systolic and diastolic BP of $131.66 \mathrm{~mm} \mathrm{Hg}$ (95\% CI, 126.78$136.53 \mathrm{~mm} \mathrm{Hg}$ ) and $83.27 \mathrm{~mm} \mathrm{Hg}$ (95\% CI, 81.53-85.02 mm Hg), respectively. More than half of the participants (57.25\%) had been diagnosed with HTN for more than 5 years (mean, 8.46 years; 95\% CI, 6.68-10.25 years). Almost two-thirds of the participants (64.4\%) were treated with only one A-HTNM once a day (64.84\%), while $35.6 \%$ were treated with two or more medications twice or several times a day (35.16\%). Only $14.43 \%$ of participants had high comorbidities. Approximately $58.96 \%$ of the participants considered that their BP is controlled, while $41.9 \%$ rated themselves as having a good health status in the self-rated health questionnaire (Tables 2,3).

\section{Prevalence of Adherence and Non-adherence}

The participants were divided into three groups according to their MMAS-8 scores: non-adherent $(\geq 3 / 8)$, moderately adherent (1-2/8), and adherent (0/8). Approximately $32 \%$ (95\% CI, 28\%-36\%) and $32 \%$ (95\% CI, 26\%-42\%) of the respondents were classified as moderately adherent and non-adherent, respectively, while 34\% (95\% CI, 28\%$41 \%$ ) were adherent. The MMAS-8 scale responses were dichotomized into optimal adherence (0/8) and suboptimal adherence (A-HTNM non-adherent) ( $\geq 1 / 8)$. The overall prevalence of A-HTNM non-adherence was $65.8 \%$ (95\% CI, 59.2\%-71.8\%).

\section{Relationship between Adherence Status and Predictors}

Under the standard complex survey data setting, univariable logistic regression was used to predict the association between adherence status and baseline data of the participants and other interesting explana- tory variables. Tables 4 and 5 show that participants' ages (odds ratio [OR], 1.03; 95\% CI, 1.01-1.06), education level (OR, 1.7; 95\% CI, 1.082.67), number of years since HTN diagnosis (OR, 1.88; 95\% CI, 1.043.37), number of A-HTNMs (OR, 1.43; 95\% CI, 1.02-2.00), and BP measurement (OR, 1.98; 95\% CI, 1.06-3.68) were the only factors associated significantly with adherent status.

In the prediction of other independent variables, which could be associated with medication adherence status, Table 6 shows that self-efficacy of the participants (OR, 4.47; 95\% CI, 3.28-6.09) and social support (OR, 2.87; 95\% CI, 2.66-3.09) were the only predictors that were significantly associated with adherent status among all other studied factors.

A multiple logistic regression model was used to assess the adjusted association of predictors with adherence status. All statistically significant variables from univariate analysis at a level of 0.1 were included in the multiple logistic regression analysis. The 11 factors that were included in the model were age, education level, duration of HTN, frequency of anti-HTN medication, number of anti-HTN medications per day, other comorbidities, BP measurement, perception of BP control, self-efficacy of participants, social support, and intrinsic motivation. Four of them (duration of HTN, perception of BP control, BP measurement, and intrinsic motivation) disturbed the model; hence, they were excluded by the backward stepwise elimination method. The other seven factors remained statistically significant and were found to be associated with the risk of A-HTNM non-adherence (Table 7).

These significant predictors included the following: age (OR, 1.04;

Table 6. Univariate analysis of adherent status and explanatory variables

\begin{tabular}{|c|c|c|c|c|}
\hline Predictor & Adherent \% & Non-adherent \% & P-value (two sided) & $\begin{array}{l}\text { Unadjusted odds ratio } \\
\text { (95\% confidence interval) }\end{array}$ \\
\hline $\begin{array}{l}\text { Mean score of participants'understanding and perception } \\
\text { about hypertension }\end{array}$ & & & 0.132 & \\
\hline Good & 98.2 & 94.9 & & $3.03(0.62-14.78)$ \\
\hline Poor & 1.8 & 5.1 & & Reference \\
\hline Mean score of beliefs about medication & & & 0.455 & \\
\hline Positive & 74.4 & 77.6 & & $0.84(0.48-1.46)$ \\
\hline Negative & 25.6 & 22.4 & & Reference \\
\hline Mean score of self-efficacy of participants & & & $<0.001^{*}$ & \\
\hline Good & 84.8 & 55.5 & & $4.47(3.28-6.09)$ \\
\hline Poor & 15.2 & 44.5 & & Reference \\
\hline Mean score of intrinsic motivationparticipants & & & $0.070^{*}$ & \\
\hline High & 58.1 & 43.1 & & $1.82(0.93-3.59)$ \\
\hline Low & 41.9 & 56.9 & & Reference \\
\hline Mean score of relationships between patients and physician & & & 0.244 & \\
\hline Good & 2.1 & 3.8 & & $1.85(0.56-6.09)$ \\
\hline Poor & 97.9 & 96.2 & & Reference \\
\hline Mean score of health system support & & & 0.385 & \\
\hline Good & 46.3 & 42.1 & & $1.18(0.75-1.86)$ \\
\hline Poor & 53.7 & 57.9 & & Reference \\
\hline Mean score of social support & & & $<0.001^{*}$ & \\
\hline Good & 87.3 & 70.5 & & $2.87(2.66-3.09)$ \\
\hline Poor & 12.7 & 29.5 & & Reference \\
\hline
\end{tabular}

*Statistically significant variables at a level of 0.1 included in multivariable regression analysis. 
Table 7. Predictors that remained significant in multiple regression analysis

\begin{tabular}{|c|c|c|}
\hline Variable & $\begin{array}{l}\text { Adjusted odds ratio } \\
\text { (95\% confidence interval) }\end{array}$ & P-value \\
\hline Age & $1.04(1.03-1.06)$ & 0.002 \\
\hline Education level & & 0.030 \\
\hline |lliterate & Reference & \\
\hline Literate & $2.23(1.12-4.45)$ & \\
\hline Frequency of antihypertensive medication & & 0.010 \\
\hline zTwice & Reference & \\
\hline Once & $2.12(1.31-3.42)$ & \\
\hline No. of antihypertensive medications & & $<0.001$ \\
\hline One medication & Reference & \\
\hline$\geq 2$ medications & $2.27(1.91-2.71)$ & \\
\hline Other comorbidities & & 0.016 \\
\hline High & Reference & \\
\hline Low & $1.60(1.14-2.24)$ & \\
\hline Self-efficacy of participants & & $<0.001$ \\
\hline Poor & Reference & \\
\hline Good & $3.80(2.82-5.11)$ & \\
\hline Social support & & $<0.001$ \\
\hline Poor & Reference & \\
\hline Good & $2.26(1.79-2.84)$ & \\
\hline
\end{tabular}

By the Hosmer and Lemeshow strategy.

95\% CI, 1.03-1.06), with the odds of non-adherent status increased by 0.04 times for a 1-year decrease in age; education level (OR, 2.23; 95\% CI, 1.12-4.45), with the odds of adherent status increased by 2.23 times among literate participants compared with illiterate participants; and the number of anti-HTN medications per day (OR, 2.27; 95\% CI, 1.912.71 ), with the odds of adherent status increased by 2.27 times among patients using two or more medications compared with those taking one medication. The odds of adherent status also increased by 2.12 times among patients using medications once a day (OR, 2.12; 95\% CI, 1.31-3.42) compared with those taking the medication twice or more per day. On comparing between patients with low and high comorbidity, other comorbidities (OR, 1.60; 95\% CI, 1.14-2.24) were likely to increase the odds of adherent status by 1.6 times. Other significant explanatory factors were self-efficacy of participants (OR, 3.8; 95\% CI, 1.79-2.84) and social support (OR, 2.26; 95\% CI, 2.82-5.11). The adherent rates were increased by 3.8 and 2.26 among patients with good self-efficacy and good social support compared with those who had poor self-efficacy and social support, respectively.

\section{DISCUSSION}

HTN complications can be prevented by patients' adherence to A-HTNM. Factors such as age, sex, number of pills per day, side effects of medication, comorbid medical conditions, patient's inadequate understanding about the complications of A-HTNM, lack of social support, poor physician-patient relationship, and health care support affect adherence in different populations. ${ }^{5,7,23-25)}$

Addressing these factors is very important for successful control and management of HTN. To the best of our knowledge, this is the first study to investigate adherence to A-HTNM and its associated factors among HTN patients attending primary health care centers in the Gaza Strip. We investigated the levels of medication adherence and its predictors among 538 HTN patients attending primary health care centers in the Gaza Strip governorates.

Self-reported measures were used in this research to determine the patients' perceived response in relation to their medication adherence behavior, which met the purpose of the study and can serve as a basis for conducting an interventional controlled trial on behavioral change among non-adherent participants.

The MMAS-8 proved to be reliable, with good concurrent and predictive validity in primarily low-income HTN patients and might function as a screening tool in outpatient settings based on its own cut-off points. The scale was shown to correlate strongly with sustained behavioral change for individuals who attended counseling sessions. ${ }^{12,26)}$

Actually, there is no gold standard measure for medication adherence among the widely available measures of medication adherence used in this research. The self-report scales have been classified as an indirect and subjective measure of medication adherence. It is a low cost and simply applicable measure. Determination of medication adherence can be objective or subjective, also called as direct or indirect. The direct measure of medication adherence depends on the biological assay of the drug in body fluids (blood or urine); however, it does not provide information about intentional and unintentional reasons for medication non-adherence. By contrast, indirect measures that involve self-report measures have the potential to identify the exact reasons for patients' non-adherence and why the individual is exhibiting this behavior.

Many other indirect measures are available: pill count, pharmacy refill records, BP measurements, and Medication Events Monitoring System (MEMS). The pill count method has been criticized by researchers because many patients did not return with their pill containers on each clinic visit. In addition, some patients might combine some pills from different containers into one medication container. Moreover, some patients do not bring the real bottles, which have some remaining pills that indicate their poor adherence to medications or discard the remaining pills before their clinic visit to show their perfect adherence to the prescribed medications. Although the effectiveness of MEMS has been shown, it is an expensive measure and has a practical problem: the removal of the dosage unit is equivalent to taking the medication. Thus, the patient could open the container without taking the medications just to increase the adherence rate.

Meanwhile, because a perfect measure does not exist, a multi-measure approach can be a good solution. Still, the decision regarding choosing a suitable approach should balance reliability and practicality, especially cost-effectiveness and the purpose of the study. ${ }^{26)}$

The overall prevalence of A-HTNM non-adherence was 65.8\% (95\% CI, $59.2 \%-71.9 \%$ ). Approximately $32 \%$ and $34 \%$ of the respondents were moderately adherent and non-adherent, respectively. These values are almost lower than those of a previous study conducted in the 
West Bank of Palestine in 2013, which revealed that $28.9 \%$ and $54 \%$ had medium and poor adherence, respectively. ${ }^{27)}$ The values reported in this study fall within the range of the recorded results in the United Arab Emirates (54.4\%), Saudi Arabia (72.1\%), ${ }^{13)}$ and Pakistan (77\%). ${ }^{24)}$

In our study, age and education level were found to be significant independent factors associated with adherence, with better adherence observed in older and more educated people; this finding is in line with those of other studies. ${ }^{13,24,27)}$ Older patients could be more sensitive to the side effect and show deterioration when their medications are ignored; these reasons probably motivated them to increase their adherence to their treatment. Therefore, counseling for patients in the younger age groups should consider full and detailed explanation about the complications of HTN and the risks of poor adherence to medications. Patients with greater levels of education may have a better understanding regarding the goal of controlling their $\mathrm{BP}$ and the potential complications associated with A-HTNM non-adherence.

This study found a positive relationship between adherence and the number of pills prescribed. Patients taking only one tablet are less adherent compared with those taking multiple pills per day. This is inconsistent with what has been advocated about one tablet dosing to increase adherence. However, this finding is consistent with those of several other studies. ${ }^{13,23,24)}$ One reason for this finding could be that patients taking two or more pills recognize the severity of their disease and hence become more attentive to their treatment. In addition, taking multiple pills probably helped them avoid forgetting their medications.

We also found that high comorbidities were associated with a decrease in adherence among these patients. However, previous studies in Saudi Arabia and the United States have reported that patients with high comorbidities were more likely to adhere to multiple medications. ${ }^{13,28)}$

Social support is a construct that describes the structure of a person's social environment and the perceptible instrumental and emotional support the social environment provides. Self-efficacy is the ability of patients to take their medications in good and bad situations and their ability to integrate medication management into their daily life. ${ }^{29)}$ This study illustrates the significant effect of self-efficacy and social support on adherence to antihypertensive treatment. However, only a few studies in the Arabic region have addressed these factors, and the finding is consistent with those of several other studies conducted in different countries. ${ }^{30)}$

Although this study is the first study in the Gaza Strip that used the survey method to assess medication adherence, several limitations were observed. First, this study did not consider all factors associated with A-HTNM adherence. Therefore, a qualitative approach and exploration of more factors may provide additional information for AHTNM adherence. Second, we did not determine the number of other medications that the patients were taking beside A-HTNM. Third, we did not discuss the classes of A-HTNM and were only concerned about the number of A-HTNM.

In conclusion, adherence to antihypertensive treatment is low among HTN patients attending primary health care clinics in the Gaza Strip, Palestine. Therefore, screening for non-adherence to A-HTNM should be a part of the routine care in primary health care clinics.

Older age, higher education level, multiple pills per day, low comorbidities, good self-efficacy, and social support were considered as predictors of higher adherence. Thus, more attention should be given to younger and less educated patients. As the same as, attention should be paid to participants who take only one pill a day, had high comorbidities and complain of poor self-efficacy and social support. Due to the multiple factors associated with non-adherence, interventions for improving adherence rate should be mainly directly toward the individuals themselves to increase their ability to challenge and cross this gap regardless of the life situations they are facing.

\section{CONFLICT OF INTEREST}

No potential conflict of interest relevant to this article was reported.

\section{ACKNOWLEDGMENTS}

The researchers would like to thank the Palestinian Ministry of Health and the General Administration of Primary Health Care. This study was approved by the Tehran University of Medical Sciences Ethical Committee and the Palestinian Health Research Council. The researchers are grateful to them.

\section{ORCID}

Khalid Khadoura: https://orcid.org/0000-0002-9538-2296

Elham Shakibazadeh: https://orcid.org/0000-0002-1320-2133

Mohammad Ali Mansournia: https://orcid.org/0000-0003-3343-2718

Yousef Aljeesh: https://orcid.org/0000-0003-0657-426X

Akbar Fotouhi: https://orcid.org/0000-0002-6438-6833

\section{REFERENCES}

1. Mosleh M, Aljeesh YI, Dalal K. Burden of chronic disease in the Palestinian healthcare sector using Disability-Adjusted Life Years (DALY), Palestine. Divers Equal Health Care 2016;13:261-8.

2. Khdour MR, Hallak HO, Shaeen M, Jarab AS, Al-Shahed QN. Prevalence, awareness, treatment and control of hypertension in the Palestinian population. J Hum Hypertens 2013;27:623-8.

3. James PA, Oparil S, Carter BL, Cushman WC, Dennison-Himmelfarb C, Handler J, et al. 2014 Evidence-based guideline for the management of high blood pressure in adults: report from the panel members appointed to the Eighth Joint National Committee (JNC 8). JAMA 2014;311:507-20.

4. Whelton PK, Carey RM, Aronow WS, Casey DE Jr, Collins KJ, Dennison Himmelfarb C, et al. 2017 ACC/AHA/AAPA/ABC/ACPM/AGS/APhA/ ASH/ASPC/NMA/PCNA guideline for the prevention, detection, evaluation, and management of high blood pressure in adults: a report of the American College of Cardiology/American Heart Association Task 
Force on Clinical Practice Guidelines. J Am Coll Cardiol 2018;71:e127248.

5. Gosmanova EO, Kovesdy CP. Adherence to antihypertensive medications: is prescribing the right pill enough? Nephrol Dial Transplant 2015;30:1649-56.

6. Blackwell B. Drug therapy: patient compliance. N Engl J Med 1973; 289:249-52.

7. Sabate E. Adherence to long-term therapies: evidence for action. Geneva: World Health Organization; 2003.

8. Elliott WJ. Improving outcomes in hypertensive patients: focus on adherence and persistence with antihypertensive therapy. J Clin Hypertens (Greenwich) 2009;11:376-82.

9. Abegaz TM, Shehab A, Gebreyohannes EA, Bhagavathula AS, Elnour AA. Nonadherence to antihypertensive drugs: a systematic review and meta-analysis. Medicine (Baltimore) 2017;96:e5641.

10. World Health organization. World Health Day 2013. Geneva: World Health Organization; 2013.

11. Kamran A, Sadeghieh Ahari S, Biria M, Malepour A, Heydari H. Determinants of patient's adherence to hypertension medications: application of health belief model among rural patients. Ann Med Health Sci Res 2014;4:922-7.

12. Morisky DE, Ang A, Krousel-Wood M, Ward HJ. Predictive validity of a medication adherence measure in an outpatient setting. J Clin Hypertens (Greenwich) 2008;10:348-54.

13. Alsolami F, Correa-Velez I, Hou XY. Factors affecting antihypertensive medications adherence among hypertensive patients in Saudi Arabia. Am J Med Med Sci 2015;5:181-9.

14. Sjolander M, Eriksson M, Glader EL. The association between patients' beliefs about medicines and adherence to drug treatment after stroke: a cross-sectional questionnaire survey. BMJ Open 2013;3: e003551.

15. Warren-Findlow J, Seymour RB, Brunner Huber LR. The association between self-efficacy and hypertension self-care activities among African American adults. J Community Health 2012;37:15-24.

16. Pelletier LG, Tuson KM, Haddad NK. Client motivation for therapy scale: a measure of intrinsic motivation, extrinsic motivation, and amotivation for therapy. J Pers Assess 1997;68:414-35.

17. Van der Feltz-Cornelis CM, van Oppen P, van Marwijk HW, de Beurs E, van Dyck R. A patient-doctor relationship questionnaire (PDRQ-9) in primary care: development and psychometric evaluation. Gen Hosp Psychiatry 2004;26:115-20.

18. Ogedegbe C, Nyirenda T, Delmoro G, Yamin E, Feldman J. Health care workers and disaster preparedness: barriers to and facilitators of willingness to respond. Int J Emerg Med 2012;5:29.

19. World Health Organization. Process of translation and adaptation of instruments. Geneva: World Health Organization; 2018.

20. Charlson ME, Pompei P, Ales KL, MacKenzie CR. A new method of classifying prognostic comorbidity in longitudinal studies: development and validation. J Chronic Dis 1987;40:373-83.

21. Koo TK, Li MY. A guideline of selecting and reporting intraclass correlation coefficients for reliability research. J Chiropr Med 2016;15:15563.

22. Abed Y, Abu-Haddaf S. Risk factors of hypertension at UNRWA primary health care centers in Gaza governorates. ISRN Epidemiol 2013;2013:720760.

23. Choi HY, Oh IJ, Lee JA, Lim J, Kim YS, Jeon TH, et al. Factors affecting adherence to antihypertensive medication. Korean J Fam Med 2018; 39:325-32.

24. Hashmi SK, Afridi MB, Abbas K, Sajwani RA, Saleheen D, Frossard PM, et al. Factors associated with adherence to anti-hypertensive treatment in Pakistan. PLoS One 2007;2:e280.

25. Osterberg L, Blaschke T. Adherence to medication. N Engl J Med 2005;353:487-97.

26. Lam WY, Fresco P. Medication adherence measures: an overview. Biomed Res Int 2015;2015:217047.

27. Al-Ramahi R. Adherence to medications and associated factors: a cross-sectional study among Palestinian hypertensive patients. J Epidemiol Glob Health 2015;5:125-32.

28. An J, Nichol MB. Multiple medication adherence and its effect on clinical outcomes among patients with comorbid type 2 diabetes and hypertension. Med Care 2013;51:879-87.

29. Criswell TJ, Weber CA, Xu Y, Carter BL. Effect of self-efficacy and social support on adherence to antihypertensive drugs. Pharmacotherapy 2010;30:432-41.

30. Magrin ME, D’Addario M, Greco A, Miglioretti M, Sarini M, Scrignaro $\mathrm{M}$, et al. Social support and adherence to treatment in hypertensive patients: a meta-analysis. Ann Behav Med 2015;49:307-18. 